\title{
Commentary: Different paradigm, but excellent results
}

\author{
John S. Ikonomidis, MD, PhD
}

I read with great interest the excellent review by Tanemoto and colleagues ${ }^{1}$ regarding the evolution and progression of cardiovascular surgery training in Japan. While it is difficult to describe all of the nuances of an entire training paradigm in one manuscript, the authors did well in providing a highly detailed summary with illustrative figures and tables. It is always interesting to examine the training programs of other countries, and consideration of the process in Japan is no exception, as the paradigm described is substantially different than that of the United States.

To highlight a few points and contrasts, there are 422 core training and 120 satellite training programs in Japan that graduate approximately 160 surgeons per year to serve a population of 120 million people. In contrast, there are approximately 95 training programs in the United States that graduate around 120 surgeons per year to serve a population of 331 million people. While the minimum period of residency is 3 years, most continue for 4 to 7 years to meet their training requirements, in part because most institutions do not do more than 100 to 250 cases per year. The average time spent in training is 9 years. In 2019, an integrated training system was implemented in an effort to decrease the training period. Most $(70 \%)$ graduating residents have logged 100 index cases. This in contrast to the American system, where residents are required to log a minimum of 125 cases per year of training. Also, in contrast to the US

From the Division of Cardiothoracic Surgery, University of North Carolina at Chapel Hill, Chapel Hill, NC.

Supported by the funding sources National Institutes of Health/National Heart, Lung, and Blood Institute grants 2R01HL102121 and 1R21HL148363.

Disclosures: The author reported no conflicts of interest.

The Journal policy requires editors and reviewers to disclose conflicts of interest and to decline handling or reviewing manuscripts for which they may have a conflict of interest. The editors and reviewers of this article have no conflicts of interest.

Received for publication Dec 23, 2020; revisions received Dec 23, 2020; accepted for publication Dec 23, 2020; available ahead of print Jan 8, 2021.

Address for reprints: John S. Ikonomidis, MD, PhD, Division of Cardiothoracic Surgery, University of North Carolina at Chapel Hill, 3034 Burnett Womack Building, 160 Dental Circle, Chapel Hill, NC 27599-7065 (E-mail: john_ikonomidis@med. unc.edu).

J Thorac Cardiovasc Surg 2022;163:176-7

$0022-5223 / \$ 36.00$

Copyright (c) 2021 by The American Association for Thoracic Surgery

https://doi.org/10.1016/j.jtcvs.2020.12.119

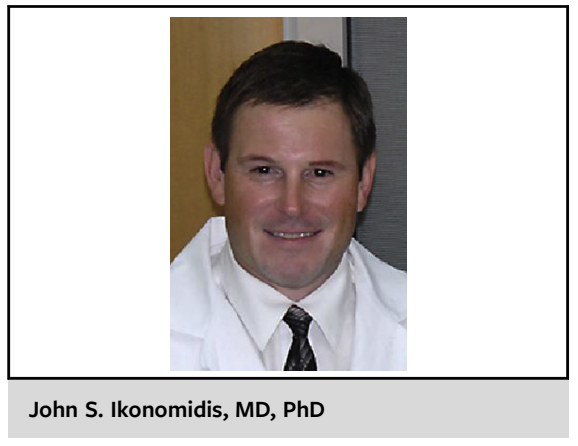

CENTRAL MESSAGE

Cardiovascular surgery training in

Japan is examined.

system, where the 80-hour work rule has been in effect for some time, there are no work-hour restrictions in the Japanese programs, but in 2023 plans are in place to implement an overtime work restriction of 1860 hours per year. The definition of overtime was not given in the manuscript. The pass rate on the written Board examination is around $80 \%$, and there is no oral component. As there are relatively few purely private-practice programs in Japan, graduating residents typically stay on at their training institutions and continue to gain experience until deemed ready for independent practice.

To summarize, cardiovascular surgery training in Japan continues to evolve. It is difficult to understand why there are so many training programs, but residents often rotate through several different hospitals (each recognized as a training program) during their training. In addition, the significant heterogeneity of case numbers may pose an issue for the new integrated residency training program, which seeks to shorten training length. Time will tell whether this paradigm is a viable option in this training environment. It would seem appropriate to consider reducing the number of training programs and increasing case requirements for the residents so that they acquire more surgical experience during training, but this change would likely be an enormous and untenable task that would involve regionalization and consolidation of cardiovascular surgery programs on the front end. Consideration could be given to the formation of an overarching Residency Review Committee, which can oversee all programs and put in place measures to standardize training expectations and education across the country. Having said all of this, the Japanese cardiovascular surgery training program has graduated some of the most 
skilled and innovative surgeons in the world, suggesting that perhaps one should not attempt to fix what is not by any means broken.

\section{Reference}

1. Tanemoto K, Yokoyama H, Okita Y, Ueda Y, Takamoto S, Yaku H, et al. Cardiovascular surgery training in Japan. J Thorac Cardiovasc Surg. 2022;163:166-75.e5.
See Article page 166.

\section{Commentary: Cardiothoracic surgery training: Global challenges without universal solutions}

\author{
Johannes R. Kratz, MD, and Tom C. Nguyen, MD
}

The goal of all medical training programs regardless of specialty is the same: to produce ethical physicians competent to practice independently in as short a timeframe as possible. How this goal is achieved varies, depending on the specific demands of the specialty in question. For cardiothoracic surgery, the road to this goal has become bumpy as of late, owing to a variety of pressures faced by both our profession and our trainees. In the United States, we are confronted with a rapidly evolving technical and clinical skillset as nonsurgical interventions increase the pressure to perform more minimally invasive techniques in patients with increasingly severe pathophysiology and disease states. At the same time, continually rising health care costs, coupled with the desire to provide just care to all, demand that we provide a higher level of service and better outcomes despite increasing economic constraints. Finally, the opportunity costs incurred by our trainees to pursue careers in cardiothoracic surgery, combined with our desire to attract the best and the brightest, demand that we provide the highest possible level of training in the shortest and most efficient timeframe possible. When considered independently, each of these pressures poses a

\footnotetext{
From the Division of Cardiothoracic Surgery, Department of Surgery, University of California San Francisco, San Francisco, Calif

Disclosures: The authors reported no conflicts of interest.

The Journal policy requires editors and reviewers to disclose conflicts of interest and to decline handling or reviewing manuscripts for which they may have a conflict of interest. The editors and reviewers of this article have no conflicts of interest.

Received for publication Jan 9, 2021; revisions received Jan 9, 2021; accepted for publication Jan 11, 2021; available ahead of print Jan 20, 2021.

Address for reprints: Johannes R. Kratz, MD, Division of Cardiothoracic Surgery, Department of Surgery, University of California San Francisco, San Francisco, CA (E-mail: johannes.kratz@ucsf.edu).

J Thorac Cardiovasc Surg 2022;163:177-8

$0022-5223 / \$ 36.00$

Copyright (C) 2021 by The American Association for Thoracic Surgery

https://doi.org/10.1016/j.jtcvs.2021.01.048
}

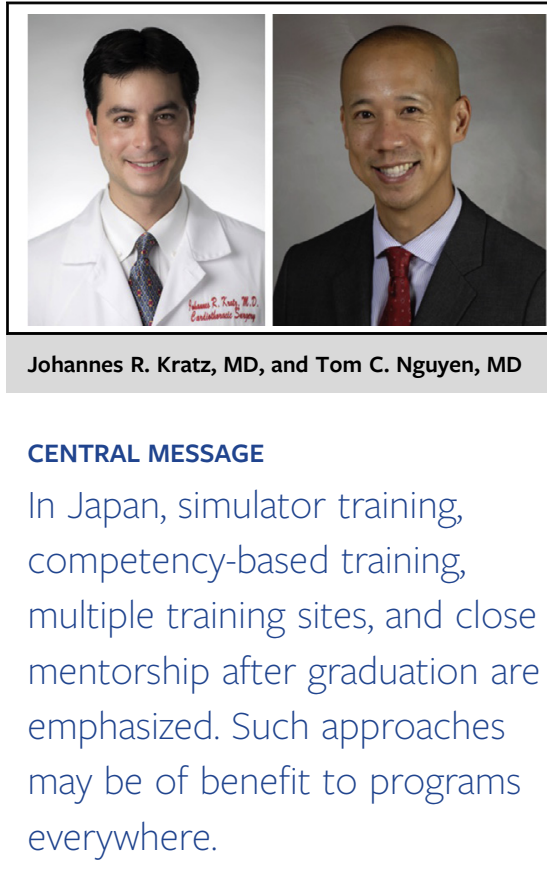

formidable challenge to formal cardiothoracic surgery training. Taken together, however, these pressures pose a unique challenge for us as educators because they are often at odds with one another. For example, one convenient way to ensure higher quality and lower cost outcomes is to have attendings do more of the case and make more of the decisions surrounding perioperative care. Resident training and progress may be adversely affected however, and this model is therefore at odds with our desire to make training as efficient and short as possible. Training programs are often faced with the unenviable task of balancing amongst evils in order to achieve the greatest common good.

These challenges are not unique to training programs in the United States, Tanemoto and colleagues face similar pressures in Japan. ${ }^{1}$ The authors describe the all-toofamiliar difficulties of decreasing case volume, increasing patient and case complexity, decreasing operative times due to economic constraints, and reduced training time to remain attractive to the most talented medical students. 